\title{
Helicobacter pylori infection and severity of coronary atherosclerosis in patients with chronic coronary artery disease
}

This article was published in the following Dove Press journal:

Therapeutics and Clinical Risk Management

27 July 2017

Number of times this article has been viewed

\author{
Anita Jukic ${ }^{1,2}$ \\ Dorotea Bozic ${ }^{3,4}$ \\ Dusko Kardum ${ }^{5,6}$ \\ Tina Becic ${ }^{1,2}$ \\ Bruno Luksic ${ }^{7,8}$ \\ Mislav Vrsalovic ${ }^{9,10}$ \\ Marko Ljubkovic" \\ Damir Fabijanic ${ }^{1,2}$
}

'Department of Cardiology, University Hospital of Split, ${ }^{2}$ Department of Cardiology, University of Split School of Medicine, ${ }^{3}$ Department of Gastroenterology, University Hospital of Split, ${ }^{4}$ Department of Gastroenterology, University of Split School of Medicine, Split, ${ }^{5}$ Department of Gastroenterology, University Hospital Dubrava, Zagreb, ${ }^{6}$ Department of Gastroenterology, University of Osijek School of Medicine, Osijek, ${ }^{7}$ Department of Surgery, University Hospital of Split, ${ }^{8}$ Department of Surgery, University of Split School of Medicine, Split, ${ }^{9}$ Department of Vascular Medicine, Cardiovascular Center, Sestre Milosrdnice University Hospital, ${ }^{10}$ Department of Vascular Medicine, University of Zagreb School of Medicine, Zagreb, "'Department of Integrative Physiology, University of Split School of Medicine, Split, Croatia

Correspondence: Damir Fabijanic Department of Cardiology, University Hospital of Split, Spinčićeva I, 21000 Split, Croatia

Tel +385 2l 556766

Fax +385 2I 55603 I

Email damir.fabijanic@st.t-com.hr
Aim: Controversy exists concerning the relation between Helicobacter pylori (HP) infection and coronary artery disease (CAD). We aimed to examine the relationship between HP infection and severity of coronary atherosclerosis in patients with chronic CAD.

Patients and methods: A total of 150 patients (109 [73\%] men; mean age $62.61 \pm 10.23$ years) scheduled for coronary artery bypass grafting surgery were consecutively enrolled in the cross-sectional study. According to rapid urease test and/or gastric biopsy samples stained with hematoxylin and eosin and according to Giemsa, patients were classified as HP positive $(\mathrm{n}=87 ; 58 \%)$ or HP negative $(\mathrm{n}=63 ; 42 \%)$. Coronary angiograms were scored by quantitative assessment, using multiple angiographic scoring system: 1) vessel score (number of coronary arteries stenosed $\geq 50 \%$ ), 2) Gensini score (assigning a severity score to each coronary stenosis according to the degree of luminal narrowing and its topographic importance) and 3) angiographic severity score (number of coronary artery segments stenosed $\geq 50 \%$ ).

Results: In comparison to HP-negative patients, HP-positive patients were more frequently hypertensive $(P=0.014)$, had higher values of systolic $(P=0.043)$ and diastolic $(P=0.005)$ blood pressure and total cholesterol $(P=0.013)$ and had lower values of high-density lipoproteincholesterol (HDL-C; $P=0.010$ ). There were no significant differences between the groups in the severity of coronary atherosclerosis: vessel score $(P=0.152)$, Gensini score $(P=0.870)$ and angiographic severity score $(P=0.734)$.

Conclusion: It is likely that HP infection is not a risk factor for the severity of coronary atherosclerosis in chronic CAD patients.

Keywords: atherosclerosis, coronary artery disease, Helicobacter pylori

\section{Introduction}

A hypothesis that a marked decline in the annual mortality from acute myocardial infarction (AMI), observed in the US since 1970s, might be associated with the reduction of duodenal peptic ulcer and improved Helicobacter pylori (HP) eradication, and the latest meta-analysis that confirmed the positive association between HP infection and an increased risk of AMI actualizes the theory about HP infection as a potential factor in the pathogenesis of coronary artery disease (CAD). ${ }^{1,2}$ Moreover, a recent report by Zuin et $\mathrm{al}^{3}$ suggested $\mathrm{HP}$ eradication as a measure in the primary and secondary CAD prevention.

Literature data concerning the relation of the HP infection with CAD are still controversial, reporting a strong positive association, ${ }^{4,6}$ a mild association ${ }^{7}$ and even negative findings. ${ }^{8-11}$ Results of the meta-analysis of the clinical studies suggest a closer relationship between the HP infection and the risk and outcomes of AMI and 
acute coronary syndrome (ACS). ${ }^{2}$ At the same time, data regarding a link between HP infection and chronic CAD are inconsistent. ${ }^{4-13}$ Therefore, we aimed to test a correlation between HP infection and the severity of coronary atherosclerosis in patients with chronic CAD. Assuming that HP infection represents an independent CAD risk factor, more severe coronary atherosclerosis was expected in HPpositive patients.

\section{Patients and methods}

A total of 150 consecutive patients (109 [73\%] men; mean age $62.61 \pm 10.23$ years) who underwent coronary artery bypass grafting (CABG) surgery were enrolled in the crosssectional observational study. Patients with a history of HP eradication, immunological diseases, malignancies, ACS and percutaneous or surgical revascularization were excluded. The study was conducted according to the principles of the Declaration of Helsinki and was approved by the ethics committee of the University Hospital of Split. All participants gave their written informed consent.

\section{Collection of data and CAD risk factors definition}

Trained research assistants filled out the questionnaire on demographic characteristics (age, gender, height, weight), presence of coronary risk factors (smoking, diabetes, hypertension, hyperlipidemia, obesity) and use of medications with known impact on atherogenesis (beta-blockers [BBs], statins, angiotensin-converting enzyme inhibitors [ACE-Is], angiotensin receptor blockers [ARBs] and calcium channel blockers [CCBs]). Coronary risk factors were defined as 1) diabetes mellitus: fasting blood glucose $>6.9 \mathrm{mmol} / \mathrm{L}$ or a non-fasting glucose $>11 \mathrm{mmol} / \mathrm{L}$ and/ or the use of antidiabetic medication; 2) hypertension: systolic blood pressure $>140 \mathrm{mmHg}$, diastolic blood pressure $>90 \mathrm{mmHg}$ or the use of antihypertensive drugs; 3 ) hyperlipidemia: total cholesterol $(\mathrm{TC})>5.0 \mathrm{mmol} / \mathrm{L}$, lowdensity lipoprotein-cholesterol (LDL-C) $>3.0 \mathrm{mmol} / \mathrm{L}$, or the use of lipid-lowering therapy; 4) overweight: BMI (weight/ height $\left.^{2}\right)>25 \mathrm{~kg} / \mathrm{m}^{2}$ and 5) smoking: categorized as nonsmoking or smoking (ie, current or stopped $<1$ year ago).

\section{Esophagogastroduodenoscopy and HP testing}

Esophagogastroduodenoscopy (EGDS; Olympus FB-25K; Olympus Corporation, Tokyo, Japan) was performed before the surgery in all patients, in order to probe for the presence of upper gastrointestinal lesions and determine the HP status.
It was conducted under local anesthesia (Xylocain spray; Astra, Wedel, Germany) by two experienced endoscopists. Biopsy samples were obtained from the antrum and body of the stomach (two samples from each region), and HP was detected by staining with hematoxylin and eosin and according to Giemsa. Additional two samples were obtained from the antrum for rapid urease test (CLOtest; Delta West Ltd., Perth, Australia). Patients were considered HP positive when either histology or the rapid urease test was positive.

\section{Coronary angiography and determination of the extent and severity of coronary atherosclerosis}

Angiographic scoring was performed according to three criteria: 1) vessel score: number of vessels with $\geq 50 \%$ stenosis of the lumen; 2) Gensini score: a severity score for each coronary artery stenosis, according to the degree of luminal narrowing and its topographic importance ${ }^{14}$ and 3) angiographic severity score: number of coronary artery segments with a stenosis $\geq 50 \%$, according to the American College of Cardiology/American Heart Association's 16 segments model of the coronary tree. ${ }^{15}$

\section{Statistical analysis}

Categorical data are presented as counts or proportions (percentages), and continuous data are presented as mean \pm SD and median (25th-75th percentile). Data were tested for normal distribution using the Kolmogorov-Smirnov test. Continuous variables with normal distribution were compared by Student's $t$-test and Mann-Whitney $U$-test if distribution was not normal. Differences between the categorical variables were tested using the chi-square test or Fisher's exact test. Mean values were compared by analysis of variance (ANOVA) for normally distributed variables and Kruskal-Wallis test for non-normally distributed ones. All statistical analyses were two sided. Spearman's correlation test was performed to test correlation between coronary risk factors and angiographic indicators of CAD severity. Statistical significance was presented with coefficient of correlation $(\rho)$ and the corresponding $P$-value. $P$-value $<0.05$ was considered as statistically significant. Statistical analyses were performed using the Statistical Package for the Social Sciences (SPSS) for Windows, version 19.0 (IBM Corporation, Armonk, NY, USA).

\section{Results}

Demographic and clinical variables of the included patients are presented in Table 1. HP positivity was observed in 
Table I Clinical and demographic characteristics of CAD patients with and without HP infection

\begin{tabular}{|c|c|c|c|}
\hline & $\begin{array}{l}\mathrm{HP}+\text {, } \\
\mathrm{n}=87 \text { (58\%) }\end{array}$ & $\begin{array}{l}\text { HP-, } \\
n=63 \text { (42\%) }\end{array}$ & $P$-value \\
\hline Age (years) & $62.51 \pm 10.33$ & $62.74 \pm 10.18$ & 0.894 \\
\hline Men & $66(6 I)$ & $43(39)$ & 0.397 \\
\hline BMI $\left(\mathrm{kg} / \mathrm{m}^{2}\right)$ & $27.8 \pm 3.6$ & $27.7 \pm 3.9$ & 0.734 \\
\hline Cigarette smoking & $27(3 \mathrm{I})$ & $16(25)$ & 0.568 \\
\hline Hypertension & $75(86)$ & $43(68)$ & 0.014 \\
\hline Hypercholesterolemia & $63(72)$ & $36(57)$ & 0.076 \\
\hline Diabetes mellitus & $30(34)$ & $14(22)$ & 0.148 \\
\hline Systolic blood pressure $(\mathrm{mmHg})$ & $129 \pm 16.12$ & $125 \pm|5|$. & 0.043 \\
\hline Diastolic blood pressure $(\mathrm{mmHg})$ & $78.8 \pm 11.48$ & $73.9 \pm 9.93$ & 0.005 \\
\hline Blood glucose (mmol/L) & $6.5 I \pm 2.19$ & $6.54 \pm 2.42$ & 0.779 \\
\hline $\mathrm{TC}(\mathrm{mmol} / \mathrm{L})$ & $5.14 \pm 1.77$ & $4.47 \pm 1.20$ & 0.013 \\
\hline HDL-C (mmol/L) & $1.03 \pm 0.31$ & $1.19 \pm 0.35$ & 0.010 \\
\hline LDL-C (mmol/L) & $3.12 \pm 1.37$ & $2.75 \pm 1.03$ & 0.062 \\
\hline Triglycerides (mmol/L) & $1.80 \pm 0.99$ & $1.62 \pm 0.54$ & 0.920 \\
\hline hs-CRP (mg/L) & $7.33 \pm 4.53$ & $5.82 \pm 3.54$ & 0.057 \\
\hline BBs & $75(86)$ & $53(84)$ & 0.722 \\
\hline ACE-Is/ARBs & $45(52)$ & $35(56)$ & 0.765 \\
\hline Statins & $83(95)$ & $61(97)$ & 0.864 \\
\hline $\mathrm{CCBs}$ & 3I (36) & $20(32)$ & 0.748 \\
\hline
\end{tabular}

Note: Results are expressed as $n$ (\%) or mean \pm SD.

Abbreviations: $A C E-1$, angiotensin-converting enzyme inhibitor; $A R B$, angiotensin receptor blocker; $\mathrm{BB}$, beta-blocker; $\mathrm{CAD}$, coronary artery disease; $\mathrm{CCB}$, calcium channel blocker; HDL-C, high-density lipoprotein-cholesterol; HP, Helicobacter pylori; hs-CRP, high-sensitivity C-reactive protein; LDL-C, low-density lipoproteincholesterol; TC, total cholesterol.

87 (58\%) patients. In comparison to HP-negative patients, HP-positive patients were more frequently hypertensive $(P=0.014)$, had higher values of systolic $(P=0.043)$ and diastolic $(P=0.005)$ blood pressure and TC $(P=0.013)$ and had lower values of high-density lipoprotein-cholesterol (HDL-C; $P=0.010$ ).

There were no differences between the groups in the use of medications with known impact on atherogenesis (BBs, statins, ACE-I/ARBs, CCBs; Table 1).

According to all performed methods of CAD scoring, there were no differences in the severity of coronary atherosclerosis between the HP-positive and HP-negative patients (Table 2). Specifically, no significant differences were found between the groups in the vessel score $(P=0.152)$,

Table 2 Severity of CAD in patients with and without HP infection

\begin{tabular}{llll}
\hline & $\begin{array}{l}\text { HP+, } \\
\mathbf{n}=\mathbf{8 7}(\mathbf{5 8 \%})\end{array}$ & $\begin{array}{l}\text { HP-, } \\
\mathbf{n}=\mathbf{6 3} \text { (42\%) }\end{array}$ & P-value \\
\hline Vessel score & $2(I-3)$ & $2(I-3)$ & 0.152 \\
Gensini score & $80(27-I \mid 6)$ & $56(30-97)$ & 0.870 \\
Angiographic severity score & $4(2-6)$ & $3(2-5)$ & 0.734 \\
\hline
\end{tabular}

Note: Results are expressed as median (25th-75th percentile).

Abbreviations: CAD, coronary artery disease; HP, Helicobacter pylori.
Table 3 Correlation between coronary risk factors and severity of coronary atherosclerosis - Spearman's correlation test

\begin{tabular}{|c|c|c|c|c|}
\hline & & $\begin{array}{l}\text { Vessel } \\
\text { score }\end{array}$ & $\begin{array}{l}\text { Gensini } \\
\text { score }\end{array}$ & $\begin{array}{l}\text { Angiographic } \\
\text { severity score }\end{array}$ \\
\hline \multirow[t]{2}{*}{ Age (years) } & $\rho$ & 0.082 & 0.188 & 0.288 \\
\hline & $P$ & 0.320 & 0.021 & $<0.001$ \\
\hline \multirow[t]{2}{*}{ BMI $\left(\mathrm{kg} / \mathrm{m}^{2}\right)$} & $\rho$ & 0.011 & 0.055 & 0.027 \\
\hline & $P$ & 0.895 & 0.501 & 0.747 \\
\hline Systolic blood & $\rho$ & 0.136 & 0.080 & 0.224 \\
\hline pressure $(\mathrm{mmHg})$ & $P$ & 0.001 & 0.333 & $<0.001$ \\
\hline Diastolic blood & $\rho$ & 0.070 & -0.020 & 0.016 \\
\hline pressure $(\mathrm{mmHg})$ & $P$ & 0.395 & 0.808 & 0.843 \\
\hline \multirow[t]{2}{*}{ Blood glucose (mmol/L) } & $\rho$ & 0.287 & 0.268 & $0.25 \mathrm{I}$ \\
\hline & $P$ & $<0.001$ & 0.001 & 0.002 \\
\hline \multirow[t]{2}{*}{$\mathrm{TC}(\mathrm{mmol} / \mathrm{L})$} & $\rho$ & -0.10 & -0.153 & -0.102 \\
\hline & $P$ & 0.222 & 0.061 & 0.213 \\
\hline \multirow[t]{2}{*}{ LDL-C (mmol/L) } & $\rho$ & 0.167 & 0.207 & 0.156 \\
\hline & $P$ & 0.041 & 0.011 & 0.057 \\
\hline \multirow[t]{2}{*}{ HDL-C (mmol/L) } & $\rho$ & -0.081 & -0.077 & -0.102 \\
\hline & $P$ & 0.537 & 0.349 & 0.213 \\
\hline \multirow[t]{2}{*}{ Triglycerides (mmol/L) } & $\rho$ & 0.038 & -0.028 & -0.016 \\
\hline & $P$ & 0.644 & 0.731 & 0.843 \\
\hline \multirow[t]{2}{*}{ hs-CRP (mg/L) } & $\rho$ & 0.133 & 0.197 & 0.181 \\
\hline & $P$ & 0.106 & 0.016 & 0.026 \\
\hline
\end{tabular}

Note: $\rho$, coefficient of correlation.

Abbreviations: HDL-C, high-density lipoprotein-cholesterol; hs-CRP, highsensitivity C-reactive protein; LDL-C, low-density lipoprotein-cholesterol; TC, total cholesterol.

Gensini score $(P=0.870)$ and angiographic severity score $(P=0.734)$.

Spearman's correlation test revealed a positive correlation between age, systolic blood pressure, blood glucose, LDL-C and high-sensitivity C-reactive protein (hs-CRP) and values of the angiographic indicators of CAD severity scoring (Table 3).

\section{Discussion}

In the presented study, a lack of correlation between the HP infection and the severity of coronary atherosclerosis was detected in patients suffering from chronic CAD, despite the more unfavorable CAD risk profile observed in the HP group. Therefore, according to our results, it is unlikely that $\mathrm{HP}$ infection contributes to the pathogenesis of chronic CAD, even via detrimental effect on the classic CAD risk factors.

Although HP infection is the risk factor primarily for the development of gastric disorders (eg, chronic gastritis, peptic ulcers, gastric adenocarcinoma), its potential association with a variety of extragastric diseases has been investigated. ${ }^{16-19}$ Since Mendall et $\mathrm{al}^{20}$ found serologic evidence of a correlation between HP seropositivity and CAD, HP infection has been postulated to play a potential role in 
the etiology of CAD. However, contrary to the results of the clinical studies and a recent meta-analysis that suggested a closer relationship between the HP infection and the risk and outcomes of AMI and ACS, ${ }^{2}$ data about a link between HP infection and chronic CAD are inconsistent. ${ }^{4-13}$

Concordantly with our results, Ozdogru et $\mathrm{al}^{10}$ and Jia et al, ${ }^{11}$ using Gensini score, found no significant correlation between HP seropositivity (HP IgG titer) and angiographically evaluated severity of coronary atherosclerosis. Contrary, using the extent score, Niccoli et $\mathrm{al}^{6}$ demonstrated a correlation between cytotoxin-associated gene A (CagA) antibody titer and severity of coronary atherosclerosis. In addition, despite an equal prevalence of HP seropositivity in subjects with and without CAD, Tsai and Huang ${ }^{12}$ observed somewhat higher tendency of HP positivity among the CAD patients with triple vessel disease than those with double and single vessel disease. Two more recent studies investigated a possible link between the HP infection and coronary atherosclerosis using the coronary artery calcification score measured by computed tomography. While Park et $\mathrm{al}^{7}$ showed a positive association between the HP positivity and early coronary atherosclerosis, suggesting a possible role of HP infection in the initiation of atherogenesis, Laek et al ${ }^{13}$ reported no association between these entities.

Different observations about the link between the HP infection and severity of coronary atherosclerosis are possibly due to differences in defining CAD, selection bias of controls, methods used for detection of HP and imaging methods and scoring systems used for estimating the CAD severity. Therefore, in order to reduce the impact of methodological variety and potential drawbacks, in the presented study, we have investigated the relationship between histologically proven HP infection and the severity of coronary atherosclerosis in patients with chronic CAD using multiple angiographic scoring system.

In relation to the association between the HP infection and CAD pathogenesis, some studies have previously demonstrated a potential link between HP infection and certain CAD risk factors. Namely, it has been reported that HP infection affects the lipid profile, mainly through the decrease of the HDL-C values, and is associated with impaired insulin secretion and arterial hypertension. ${ }^{11,21,22}$ In addition, HP might influence atherogenesis via stimulating chronic inflammation. ${ }^{23}$ Moreover, there are reports about alteration of some clinical and biochemical parameters related to CAD that occurred after HP eradication, suggesting the HP eradication as a potentially useful method in the prevention of CAD, especially in the developing countries. ${ }^{24-26}$ In this regard, our results are similar to the study by Jia et al, ${ }^{11}$ in which a positive correlation between the HP positivity and severity of coronary atherosclerosis has not been observed, despite a positive association detected between the HP infection and decreased serum levels of HDL-C. In addition, similar to our observation, an association between the HP infection and arterial hypertension has been found in some previous studies; however, no causative link has yet been proposed between these entities. ${ }^{22,24}$ Using Spearman's correlation test, we observed a positive correlation between age, systolic blood pressure, LDL-C and hs-CRP and angiographic indicators of CAD severity. Interestingly, among the mentioned CAD risk factors, only systolic blood pressure has been significantly different (higher) in HP-positive patients. Importantly, despite an observed difference in blood pressure values between HP-positive and HP negative patients, the mean blood pressure levels were still below a therapeutic threshold in both groups. Additionally, all included patients have been treated according to the guidelines for treatment of stable CAD and no differences between the two groups were present pertaining to use of medications known to have an effect on atherogenesis. ${ }^{15}$ Therefore, according to our results and the results of the abovementioned studies, it is unlikely that the HP infection contributes to the pathogenesis of chronic CAD, even through the modifications of the traditional CAD risk factors.

Even though our study suggests that the HP infection is likely not an independent risk factor for the severity of coronary atherosclerosis in chronic CAD patients, our results do not exclude the possible association between HP infection and acute coronary events. Namely, despite being the standard for evaluation of the severity of CAD, coronary angiography does not enable full characterization of the detected atherosclerotic plaque in the coronary artery wall, its activity and rupture tendency. Although colonization of coronary atherosclerotic plaques with HP has been observed using polymerase chain reaction (PCR), it has been demonstrated that the rate of HP-infected plaques is significantly lower than the HP positivity detected by serology or gastric mucosa biopsy and is dominantly associated with the vulnerability of atherosclerotic plaques. ${ }^{27-29}$

Therefore, taking into consideration the results presented here and the results of some previous studies and their metaanalyses, it is likely that the HP infection in the atherosclerotic naive young population, through inflammatory and immunologic mechanisms, may initiate development of the atherosclerotic lesion(s), while in patients with vulnerable atherosclerotic plaques, it may provoke the plaque rupture 
and onset of the ACS. ${ }^{2}$ Therefore, according to the current data, it seems that in the context of CAD prevention, the latter group of patients might benefit most from HP eradication.

\section{Limitations of the study}

Potential limitation of the study is the lack of confirmation of CagA seropositivity. However, it is important that a number of previous studies did not find a strong relationship between CagA seropositivity and either CAD or its risk factors (blood pressure, lipid profile, homocysteine level, fibrinogen) after adjustment for confounding factors. ${ }^{30-32}$

\section{Conclusion}

Our results suggest that HP infection is likely not an independent risk factor for the severity of coronary atherosclerosis in chronic CAD patients. It seems that in the multifactorial pathogenesis of stable chronic $\mathrm{CAD}$, traditional risk factors surpass potential impact of HP infection.

\section{Author contributions}

All authors contributed toward data analysis, drafting and critically revising the paper and agree to be accountable for all aspects of the work.

\section{Disclosure}

The authors report no conflicts of interest in this work.

\section{References}

1. Hughes WS. An hypothesis: the dramatic decline in heart attacks in the United States is temporally related to the decline in duodenal ulcer disease and Helicobacter pylori infection. Helicobacter. 2014;19(3): 239-241.

2. Liu J, Wang F, Shi S. Helicobacter pylori infection increase the risk of myocardial infarction: a meta-analysis of 26 studies involving more than 20.000 participants. Helicobacter. 2015;20(3):176-183.

3. Zuin M, Rigatelli G, Del Favero G, et al. Coronary artery disease and Helicobacter pylori infection: should we consider eradication therapy as cardiovascular prevention strategy? Int J Cardiol. 2016;223: 711-712.

4. Koenig W, Rothenbacher D, Hoffmeister A, et al. Infection with Helicobacter pylori is not a major independent risk factor for stable coronary heart disease: lack of a role of cytotoxin-associated protein A-positive strains and absence of a systemic inflammatory response. Circulation. 1999;100(23):2326-2331.

5. Rogha M, Nikvarz M, Pourmoghaddas Z, Shirneshan K, Dadkhah D, Pourmoghaddas M. Is Helicobacter pylori infection a risk factor for coronary heart disease? ARYA Atheroscler. 2012;8:5-8.

6. Niccoli G, Franceschi F, Cosentino N, et al. Coronary atherosclerotic burden in patients with infection by CagA-positive strains of Helicobacter pylori. Coron Artery Dis. 2010;21(4):217-221.

7. Park MJ, Choi SH, Kim D, et al. Association between Helicobacter pylori seropositivity and the coronary artery calcium score in a screening population. Gut Liver. 2011;5(3):321-327.

8. Regnström J, Jovinge S, Båvenholm $\mathrm{P}$, et al. Helicobacter pylori seropositivity is not associated with inflammatory parameters, lipid concentrations and degree of coronary artery disease. J Intern Med. 1998; 243(2):109-113.
9. Al-Nozha MM, Khalil MZ, Al-Mofleh IA, Al-Ghamdi AS. Lack of association of coronary artery disease with $H$. pylori infection. Saudi Med J. 2003;24(12):1370-1373.

10. Ozdogru I, Kalay N, Dogan A, et al. The relationship between Helicobacter pylori IgG titre and coronary atherosclerosis. Acta Cardiol. 2007;62(5):501-505.

11. Jia EZ, Zhao FJ, Hao B, et al. Helicobacter pylori infection is associated with decreased serum levels of high density lipoprotein, but not with the severity of coronary atherosclerosis. Lipids Health Dis. 2009;8:59.

12. Tsai CJ, Huang TY. Relation of Helicobacter pylori infection and angiographically demonstrated coronary artery disease. Dig Dis Sci. 2000; 45(6):1227-1232.

13. Laek B, Szklo M, McClelland RL, et al. The prospective association of Chlamydia pneumoniae and four other pathogens with development of coronary artery calcium: the multi-ethnic study of atherosclerosis (MESA). Atherosclerosis. 2013;230(2):268-274.

14. Gensini GG. A more meaningful scoring system for determinating the severity of coronary heart disease. Am J Cardiol. 1983;51(1Pt2):606.

15. Scanlon PJ, Faxon DP, Audet AM, et al. ACC/AHA guidelines for coronary angiography. A report of the American College of Cardiology/American Heart Association task force on practice guidelines (Committee on coronary angiography). Developed in collaboration with the Society for Cardiac Angiography and Interventions. J Am Coll Cardiol. 1999;33(6):1756-1824.

16. Asaoka D, Nagahara A, Shimada Y, et al. Risk factors for osteoporosis in Japan: is it associated with Helicobacter pylori? Ther Clin Risk Manag. 2015;11:381-391.

17. Chiu NC, Lin CY, Chi H, et al. Helicobacter pylori is not associated with failure to thrive: a case-control study. Ther Clin Risk Manag. 2017;13:273-278.

18. Radic M, Kaliterna DM, Bonacin D, et al. Is Helicobacter pylori infection a risk factor for disease severity in systemic sclerosis? Rheumatol Int. 2013;33(11):2943-2948.

19. Nártová E, Kraus J, Pavlík E, et al. Presence of different genotypes of Helicobacter pylori in patients with chronic tonsillitis and sleep apnoa syndrome. Eur Arch Otorhinolaryngol. 2014;271(3):607-613.

20. Mendall MA, Goggin PM, Molineaux N, et al. Relation of Helicobacter pylori infection and coronary heart disease. Br Heart J. 1994;71(5): 437-439.

21. Hoffmeister A, Rothenbacher D, Bode G, et al. Current infection with Helicobacter pylori, but not seropositivity to Chlamydia pneumoniae or Cytomegalovirus, is associated with an atherogenic, modified lipid profile. Arterioscler Thromb Vasc Biol. 2001;21(3):427-432.

22. Vahdat K, Pourbehi MR, Ostovar A, et al. Association of pathogen burden and hypertension: the Persian gulf healthy heart study. Am J Hypertens. 2013;26(9):1140-1147.

23. Rahman MA, Cope MB, Sarker SA, Garvey WT, Chaudhury HS, Khaled MA. Helicobacter pylori infection and inflammation: implication for the pathophysiology of diabetes and coronary heart disease in Asian Indians. J Life Sci. 2009;1(1):45-50.

24. Migneco A, Ojetti V, Specchia L, et al. Eradication of Helicobacter pylori infection improves blood pressure values in patients affected by hypertension. Helicobacter. 2003;8(6):585-589.

25. Pellicano R, Oliaro E, Fagoonee S, et al. Clinical and biochemical parameters related to cardiovascular disease after Helicobacter pylori eradication. Int Angiol. 2009;28(6):469-473.

26. Longo-Mbenza B, Nkondi Nsenga J, Vangu Ngoma D. Prevention of the metabolic syndrome insulin resistance and the atherosclerotic diseases in Africans infected by Helicobacter pylori infection and treated by antibiotics. Int J Cardiol. 2007;121:229-238.

27. Izadi M, Fazel M, Sharubandi SH, et al. Helicobacter species in the atherosclerotic plaques of patients with coronary artery disease. Cardiovasc Pathol. 2012;21(4):307-311.

28. Blasi F, Ranzi ML, Erba M, et al. No evidence for the presence of Helicobacter pylori in atherosclerotic plaques in abdominal aortic aneurism specimens. Atherosclerosis. 1996;126(2):339-340. 
29. Kaplan M, Yavuz SS, Cinar B, et al. Detection of chlamydia pneumoniae and Helicobacter pylori in atherosclerotic plaques of carotid artery by polymerase chain reaction. Int J Infect Dis. 2006;10(2):116-123.

30. Whincup P, Danesh J, Walker M, et al. Prospective study of potentially virulent strains of Helicobacter pylori and coronary heart disease in middle-aged men. Circulation. 2000;101(14):1647-1652.

31. Singh RK, McMahon AD, Patel H, Packard CJ, Rathbone BJ, Samani NJ. Prospective analysis of the association of infection with CagA bearing strains of Helicobacter pylori and coronary heart disease. Heart. 2002;88(1):43-46.
32. Schöttker B, Adamu MA, Weck MN, Müller H, Brenner H. Helicobacter pylori infection, chronic atrophic gastritis and major cardiovascular events: a population-based cohort study. Atherosclerosis. 2012;220(2):569-574.

\section{Publish your work in this journal}

Therapeutics and Clinical Risk Management is an international, peerreviewed journal of clinical therapeutics and risk management, focusing on concise rapid reporting of clinical studies in all therapeutic areas, outcomes, safety, and programs for the effective, safe, and sustained use of medicines. This journal is indexed on PubMed Central, CAS,
EMBase, Scopus and the Elsevier Bibliographic databases. The manuscript management system is completely online and includes a very quick and fair peer-review system, which is all easy to use. Visit http://www.dovepress.com/testimonials.php to read real quotes from published authors.

Submit your manuscript here: http://www.dovepress.com/therapeutics-and-clinical-risk-management-journal 